\title{
Passado, Presente e Futuro
}

Arquivos Brasileiros de Cardiologia são uma publicação científica que, ao longo das últimas cinco décadas, têm contribuído para a divulgação da ciência cardiovascular e da melhoria da prática cardiológica em nosso país. Recentemente, a revista tornou-se veículo de divulgação internacional da produção científica cardiovascular do Brasil e, a partir de janeiro de 1999, bilíngüe. Esta mudança de foco deve ficar bem definida para os nossos leitores e associados, particularmente os que não atuam no âmbito acadêmico. As modificações em nosso perfil editorial motivaram o número crescente de artigos menos voltados às questões utilitárias e sim à investigação cardiovascular inovadora, provenientes de teses das pós-graduações brasileiras. $\mathrm{O}$ mundo contemporâneo e globalizado tem oferecido novas e diferentes fontes para atualização do cardiologista, como: congressos, simpósios, revistas, CD-rom, vídeos, vídeo-conferências e, principalmente, a Internet. Hoje, um artigo de atualização a ser publicado nos Arquivos demora, em média, 6 a 12 meses, portanto, encontrando-se, com freqüência defasado no momento da publicação, devido ao crescimento de novas descobertas científicas, fenômeno do aumento da velocidade, já que, em média, o conhecimento no mundo dobra a cada 2 anos. A construção de um programa de contínua capacitação profissional e de atualização científica é um dos principais compromissos da Sociedade Brasileira de Cardiologia. A participação da SBC na atualização do profissional tem sido ampliada com o advento da Internet, pelo nosso "site" o www.cardiol.br, diferentes produtos, como a esquina científica, aulas e cursos de educação à distância estão disponíveis para nossos associados. Novas aberturas como Programa de Educação Continuada (PEC) coordenado pelo Prof. Edson Saad e as ações dos departamentos e dos grupos de estudo da SBC estão sendo aprimoradas para ampliar as estratégias de levar educação permanente a todos os associados da SBC.

O desenvolvimento do Brasil será cada vez mais dependente dos investimentos em educação, ciência e tecnologia, tão importantes para nossa inserção no mundo globalizado. Embora o Brasil tenha avançado no ensino básico, colocando mais crianças nas escolas, ainda existem grandes desafios educacionais a serem vencidos. Atualmente, apenas 5,8 milhões de brasileiros possuem diploma universitário e somente 304 mil o título de mestrado ou doutorado ( $0,4 \%$ da população) (fig. 1$)$. Esses números são considerados baixos se comparados aos de países desenvolvidos ou em desenvolvimento. Ao se analisar a taxa bruta de escolarização no ensino superior, ou seja, o número de graduados em comparação com a população em idade universitária, o Brasil possui uma taxa de $15 \%$ enquanto a Argentina de $36 \%$, a Austrália de $63 \%$, o Chile de $38 \%$, a França de $54 \%$, o México de $21 \%$ e os EUA de $75 \%$. As áreas que possuem o maior número de graduados são as de ciências sociais e direito $(39,8 \%)$ enquanto a área da saúde possui apenas $15 \%$.

A mudança do enfoque dos Arquivos vem sendo ela- borada e implementada há cerca de uma década, atendendo à política governamental do Ministério da Educação e às normas de avaliação dos cursos stricto-senso de pós-graduação (cursos de mestrado e doutorado) que exigem a publicação dos produtos das teses em revistas científicas de elevado impacto.

A comunidade científica brasileira encontra-se em expansão. Um número crescente de estudantes está sendo treinado em investigação científica nos cursos de pós-graduação. A cada ano o Brasil forma aproximadamente 6000 doutores, proporcionando um aumento na contribuição científica internacional, na última década, de cientistas brasileiros. No período entre 1997 e 2000, cientistas brasileiros publicaram 34,274 artigos em revistas indexadas, conforme dados do Instituto para Informação Científica (ISI) ${ }^{2}$. Porém, a nossa produção científica ainda é assimétrica; 78,5\% delaé originária de 12 universidades públicas. A avaliação dos cursos de pósgraduação stricto-senso (mestrado e doutorado) é realizada pela CAPES (Coordenaçãoe Aperfeiçoamento de Pessoal de Nível Superior) uma agência do Ministério da Educação que regulamenta os critérios de avaliação e estabelece um ranking de 1 (menor) a 7 (maior) para estes cursos. Dentre os critérios avaliados temos a análise do curriculum vitae dos professores, número de tese defendidas, tempo para defesa e se a tese foi publicada em revista de impacto (o item mais valioso). Os Arquivos são considerados pela CAPES uma das revistas científicas nacionais de grande relevância na avaliação da pós-graduação, principalmente após se tornar bilíngüe e criar novas ferramentas para agilizar o processo de revisão pelos pares de nossas publicações, como a implementação do processo de submissão e avaliação de artigos pela Internet (www.cardiol.br//publicações).

A publicação da tese é o indicador da investigação científica de qualidade. $O$ cientista investigador, a partir de uma idéia, constrói o seu projeto de pesquisa que é submetido às agências de financiamento ou à comissão científica da sua instituição. É apreciado também o seu sentido bioético (se ela deve ser feita) pelo Comitê de Ética em Pesquisa com seres humanos. Somente após cumprir todas essas etapas é iniciado o árduo trabalho de experimentação. Portanto, a submissão de um artigo para uma revista envolve um conjunto de expectativas de toda comunidade científica. $\mathrm{O}$ artigo é então analisado por um grupo de especialistas que recomenda ou não a sua publicação. Os resultados, uma vez publicados, dão origem a críticas e a novos experimentos, que confirmam ou não as observações iniciais. Este é um processo contínuo de fazer ciência cardiovascular, com seu caráter universal, que permite adquirir e comprovar novos conhecimentos e mudar paradigmas. A produção de conhecimento na área da medicina cardiovascular pode ser dividida de maneira didática em três grandes áreas: ciência básica, ciência epidemiológica e ciência clínica. Portanto, aquilo que no passado era fácil de ser analisado ganha pormeno- 


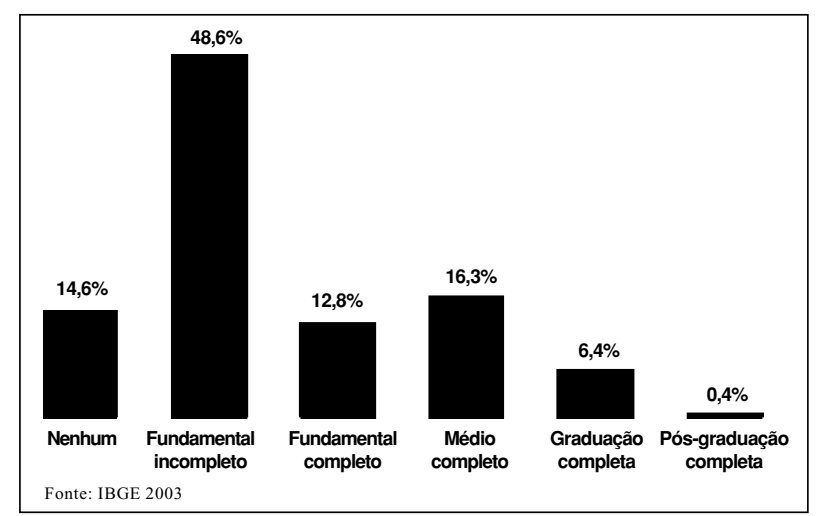

Fig. 1 - O grau de instrução do brasileiro. População com 25 anos ou mais, pelo nível de ensino.

res e os revisores especializados são de fundamental importância para construção da boa ciência. A ciência básica, particularmente aquela envolvendo as áreas de biologia celular e molecular, impõe uma forte pressão na velocidade de publicação dos seus resultados - um fenômeno mundial.

Os Arquivos têm outra importante missão: a de disseminar conceitos de redação do trabalho e metodologia da pesquisa científica, preenchendo lacunas da formação médica, principalmente entre aqueles que possuem o espírito de investigador e não receberam treinamento formal. O Brasil possui 110 escolas médicas, muitas delas com grade curricular defasada das necessidades do profissional de saúde contemporâneo. Ao lado disso, apresentam corpo docente heterogêneo e modelos didáticos-pedagógicos que não exercitam a busca e a análise crítica do conhecimento e, principalmente, não dão ênfase à inovação e criatividade, ítens muito importantes na formação do médico e base dos tradicionais programas de iniciação científica. Os nossos revisores necessitam de um comprometimento não apenas de realizarem revisões imparciais semelhantes àquelas feitas por revisores de revistas internacionais, mas também de exercerem um trabalho de parceria com nossos autores. Pois, diferentemente de centros internacionais de excelência que possuem, redatores profissionais, bio-estatísticos, epidemiologistas e revisores seniors institucionais responsáveis pela organização prévia dos textos a serem submetidos à publicação, nossos autores produzem em ambiente de escassez de infra-estrutura e com as fortes demandas assistenciais do dia-a-dia. Portanto os Arquivos devem também ter o compromisso na disseminação das técnicas de produção de conhecimento e da formação de revisores compromissados no aprimoramento dos artigos submetidos à nossa revista.

Outro importante desafio é a obtenção da acreditação do ABC junto a ISI, responsável pela análise do fator de impacto das publicações científicas. O fator de impacto é o maior bench mark de uma revista científica de sucesso. Ele é calculado baseado no número de artigos citados de uma determinada revista. Assim, para os Arquivos, o fator de impacto de 2003 , é calculado através do número de artigos pu-

\begin{tabular}{|lcc|}
\hline & \multicolumn{2}{c|}{ Anos } \\
\hline & 1999 & 2003 \\
\cline { 2 - 3 } Número de artigos publicados & 103 & 139 \\
Tempo de decisão (meses) & $2-4$ & $1-2$ \\
Tempo de publicação (meses) & $12-18$ & $6-8$ \\
Triagem (número mensal de exemplar) & 8.000 & 10.000 \\
Fator de impacto & --- & --- \\
\hline
\end{tabular}

Fig. 2 - Desempenho dos Arquivos.

blicados entre 2001 e 2002, citados na literatura médica em 2003, dividido pelo número total de artigos publicados nos ABC em 2001 e 2002. Desta forma, o índice de impacto é de grande importância dentro do perfil globalizado da medicina cardiovascular (fig. 2). Ele é reconhecido pelos centros acadêmicos e algumas instituições apenas levam em consideração aqueles artigos publicados em jornal de impacto maior que 3 (trabalho de elevada qualidade).

As seguintes mudanças estarão sendo implementadas para os próximos 2 anos, a sereminiciadas nos próximos meses:

- um novo corpo editorial constituído, por um número maior de médicos e cientistas brasileiros e internacionais, que irão se juntar ao nosso corpo editorial para tornar nossas revisões mais rápidas, ampliando o olhar especializado da cardiologia contemporânea;

- um sistema de revisão mais ágil com o objetivo de promover rápida publicação de resultados de ensaios clínicos ou de achados inovadores;

- novo projeto gráfico, mais moderno e de acordo com as tendências internacionais das revistas científicas (foto na capa, nova tipologia etc);

- as páginas na internet destinadas aos Arquivos serão modernizadas, com novas ferramentas destinadas à atualização e suporte à produção científica.

- aquisição de um novo software de busca para facilitar a localização de artigos nos Arquivos, o que facilitará a citação de artigos já publicados.

A implementação dessas e novas iniciativas requer uma sólida parceria que deverá incluir autores nacionais, coordenadores de pós-graduação estimulados a submeter suas melhores pesquisas e teses, e nossos revisores a fim de serem ágeis e compromissados com avaliações objetivas e construtivas.

Assim, nosso objetivo é de uma ativa participação dos conselhos editorial e científico do ABC, atuando na consolidação das mudanças que possibilitaram aos Arquivos, ao longo de sua histórica trajetória, tornar-se um veículo ágil, democrático e de elevada credibilidade junto à comunidade científica nacional e internacional.

Evandro Tinoco Mesquita Editor

Carlos Eduardo Suaide Silva Diretor de Comunicação

\section{Referências}

1. Méis L, VellosoA,Lannes D, Carmo MS, de M is C. BrazJMedBiol Res 2003; 36: 1135-41.
2. de Meis L, Carmo MS \& de Meis C. Impact factors: just part of a research treadmill. Nature 2003; 424: 723. 